\title{
Maspin Enhances the Anticancer Activity of Curcumin in Hormone-refractory Prostate Cancer Cells
}

\author{
WAN-LI CHENG ${ }^{1}$, CHIEN-YU HUANG ${ }^{2,3}$, CHENG-JENG TAI ${ }^{4,5}$, \\ YU-JIA CHANG ${ }^{1,2,6,7}$ and CHIN-SHENG HUNG ${ }^{1,2,6}$ \\ ${ }^{1}$ Graduate Institute of Clinical Medicine, College of Medicine, \\ Taipei Medical University, Taipei, Taiwan, R.O.C.; \\ ${ }^{2}$ Department of Surgery, School of Medicine, College of Medicine, \\ Taipei Medical University, Taipei, Taiwan, R.O.C.; \\ ${ }^{3}$ Division of General Surgery, Department of Surgery, Shuang \\ Ho Hospital, Taipei Medical University, Taipei, Taiwan, R.O.C.; \\ ${ }^{4}$ Department of Internal Medicine, School of Medicine, \\ College of Medicine, Taipei Medical University, Taipei, Taiwan, R.O.C.; \\ ${ }^{5}$ Division of Hematology and Oncology, Department of Internal Medicine, \\ Taipei Medical University Hospital, Taipei, Taiwan, R.O.C.; \\ ${ }^{6}$ Division of General Surgery, Department of Surgery, Taipei Medical University Hospital, Taipei, Taiwan, R.O.C.; \\ ${ }^{7}$ Cancer Research Center, Taipei Medical University Hospital, Taipei, Taiwan, R.O.C.
}

\begin{abstract}
Background/Aim: Androgen deprivation therapy remains the principal treatment for patients with advanced prostate cancer, though, most patients will eventually develop hormone-refractory prostate cancer (HRPC). Androgen ablation mediated maspin-induction has been identified in cancer patients. However, the role of maspin on the anticancer activity of curcumin derived from turmeric (Curcuma longa) in HRPC cells has not been elucidated. Materials and Methods: The anticancer action of curcumin in hormone-independent prostate cancer cells (DU145, and $P C$-3) was determined by measures of cell survival rate. The cause of maspin silencing on the anti-tumor abilities of curcumin in PC-3 cells was evaluated by measures of cell survival rate, cell-cycle distribution, and apoptosis signaling analysis. Results: Our present study showed that PC-3 cells (with higher maspin expression) were more sensitive than DU145 cells to curcumin treatment (with lower maspin expression). RNA interference-mediated maspin silencing reduced curcumin sensitivity of $P C-3$ cells, as evidenced by reduced apoptotic cell death. After exposure to curcumin, maspin-knockdown cells showed lower expression levels of
\end{abstract}

Correspondence to: Yu-Jia Chang and Chin-Sheng Hung, Graduate Institute of Clinical Medicine, College of Medicine, Taipei Medical University, $250 \mathrm{Wu}$-Xin Street, Taipei City, 110 Taiwan, R.O.C. Tel/Fax: +886227361661 ext. 3027, e-mail: hungcs@tmu.edu.tw

Key Words: Maspin, curcumin, hormone-refractory prostate cancer. pro-apoptotic proteins, Bad and Bax, as compared with control cells. Conclusion: Maspin can enhance the sensitivity of HRPC cells to curcumin treatment.

Prostate cancer is the most common worldwide cause of cancer death among men (1). The activation of the prostate specific antigen (PSA)/androgen receptor (AR) axis is connected with the development of prostate cancer (2). Androgen deprivation therapy is the most common treatment for advanced prostate cancer patients; however, the tumors in these patients ultimately progress and transform into hormone-refractory prostate cancer (HRPC) (3). Numerous chemotherapeutic drugs have been applied to HRPC treatment; however, improving the therapeutic efficacy of current drugs remains a significant clinical challenge in HRPC. Thus, an effective therapy is needed to prevent the progression of prostate cancer.

Curcumin, a component of Curcuma longa, is a promising chemopreventive compound (4). Furthermore, previous studies have reported that curcumin is a potent agent that possesses anti-oxidant, anti-inflammatory, anti-proliferative, and anti-angiogenic properties against several cancer cell types $(5,6)$. Curcumin also inhibits the expression of AR and AR-related cofactors (AP-1, NF-kB and CBP) in prostate cancer cell lines (7). Moreover, various curcumin analogues have been indicated to function as androgen receptor antagonists with the potential of being anti-prostate cancer agents (8). Evidence has strongly suggested that curcumin is a promising chemo-sensitizing agent for management of 
resistant tumors (9). Consequently, the combination of the use of curcumin and available anticancer agents has great potential to enhance anticancer efficacy and improve clinical outcomes for cancer treatment (10). The therapeutic prospect in treating prostate cancer has been evidenced in cell culture systems and human xenograft mouse models (11). However, additional effort is needed to fully understand the mechanism and therapeutic potential of curcumin for HRPC.

Maspin, also termed mammary serine protease inhibitor, is down-regulated in breast and prostate cancer, but overexpressed in gastric cancers, pancreatic, colorectal, and thyroid cancers (12-17). Thus, maspin may have different activities in different cancer types. Furthermore, the expression level of maspin is correlated with better prognosis in prostate and breast cancer (13). The up-regulation of maspin in response to androgen ablation suggests that it has potential functions in growth inhibition and/or apoptosis of prostate cancer cells (18). Also, Zhang et al. suggested that the tumor suppressor activity of maspin may depend on its ability to inhibit angiogenesis (19). A previous report has revealed that curcumin induces the expression of maspin in prostate cancer LNCaP cells (20). Curcumin-mediated maspin induction has been suggested to have therapeutic potential for inhibition of the invasion of breast carcinoma cells (21). Previous results also suggest that maspin could reduce prostate tumor cell plasticity and enhances tumor sensitivity to drug treatment (22). Thus, further studies are necessary to better define the therapeutic implication of maspin on curcumin treatment in HRPC.

Accumulating evidence has indicated that curcumin has therapeutic potential for cancer, and further efforts to explore this therapeutic approach appear warranted (4). Additionally, numerous studies have emphasized the essential role of maspin in cancer treatment (13). As a result, there is a need for further elucidation of the function of maspin in the curcumin treatment of hormone-independent cells. Therefore, we evaluated the functions of maspin on curcumin activity in hormone-independent prostate cancer cells.

\section{Materials and Methods}

Cell culture and chemicals. The human prostate cancer cell lines (PC-3 and DU-145 cell) were purchased from the American Type Culture Collection (ATCC) and were cultured in RPMI 1640 with $10 \%$ fetal calf serum (FCS) (Life Technologies, Grand Island, NY, USA) in a $37^{\circ} \mathrm{C}$ incubator with $5 \% \mathrm{CO}_{2}$. Curcumin was obtained from Sigma Chemical Co. (St. Louis, MO, USA).

Silenced maspin expression in prostate cancer cells. The expression of maspin in prostate cancer cells was ablated using MISSION shRNA clones (Sigma Chemical Co., St. Louis, MO, USA). MISSION shRNA clones are sequence-verified shRNA lentiviral plasmids for gene silencing in mammalian cells. The parental vector (pLKO.1<-puro) allows for stable transfection via puromycin selection. The target sequence for the human maspin mRNA
(NM_002639.4) gene is 5'-CAGATCAACAACTCAATTAAG -3' (TRCN0000373444) (Sigma Chemical Co., St. Louis, MO, USA). The MISSION non-target shRNA control vector (SHC002) was utilized as a scrambled control. The transfection protocol has been described previously (23). Briefly, $1 \times 10^{5}$ cells were washed twice with PBS and mixed with $0.5 \mu \mathrm{g}$ of plasmid. One pulse was applied for $20 \mathrm{msec}$ under a fixed voltage of $1.4 \mathrm{kV}$ on a Neon pipette-type microporator (Invitrogen Life Technologies, Grand Island, NY, USA).

Western blot analysis. Cells were treated with curcumin or vehicle control (70\% ethanol) for $48 \mathrm{~h}$. Total cell lysates were prepared, and protein concentration were determined using the method described previously (24). Western blot analysis was performed as described previously (25). Primary antibodies against Mcl-1, Bcl-2, Bax, Bad, GAPDH (Santa Cruz Biotechnology, Santa Cruz, CA, USA), and maspin (Sigma Chemical Co. St. Louis, MO, USA) were utilized for Western blotting (23).

Cell viability assay. Cell viability was quantitated using the 3-[4,5dimethylthiazol-2-yl]-3,5-diphenyl tetrazolium bromide (MTT) assay. First, cells $\left(2 \times 10^{4}\right)$ were seeded into 24 -well plates and incubated for $24 \mathrm{~h}$. Subsequently, different concentrations of curcumin $(0-30 \mu \mathrm{M})$ or vehicle control $(70 \%$ ethanol) were added to the cells. The culture medium was removed at specific times, and cells were incubated in a final concentration of $0.25 \mathrm{mg} / \mathrm{ml}$ MTT at $37^{\circ} \mathrm{C}$ for $1 \mathrm{~h}$. After discarding the supernatant, the precipitated formazan was solubilized with DMSO, and the optical density was measured at $550 \mathrm{~nm}$ using a spectrophotometer (GE Healthcare, Piscataway, NJ, USA) (26).

Flow cytometric cell-cycle analysis. Cells $\left(3 \times 10^{5} /\right.$ well $)$ were plated in 6-well plates overnight and then incubated with curcumin or vehicle control for $48 \mathrm{~h}$. At different time intervals, cells were fixed in pure methanol, stained with propidium iodide (PI), and subjected to flow cytometry (BD Biosciences, San Jose, CA, USA) as described earlier. Samples were analyzed with Modfit software (Verity Software House, Inc., Topsham, ME, USA) (23).

Annexin V-PI apoptosis detection assay. Cells $\left(5 \times 10^{5} /\right.$ well $)$ were seeded in 6-well plates and treated with curcumin or vehicle control for $48 \mathrm{~h}$. Subsequently, cells were double-stained with Annexin V-fluorescein isothiocyanate (FITC) and propidium iodide (PI) utilizing the Annexin V-FITC kit (Immunochemistry Technologies, Bloomington, MN, USA) as described previously (26). The Annexin V/PI protocol is a commonly used approach for studying apoptotic cells (27). Data were acquired with the Attune ${ }^{\circledR}$ Acoustic Focusing Cytometer system (Life Technologies, Grand Island, NY, USA). During the later stages of apoptosis, PI can readily move across the cell membrane and bind to DNA. Statistical analyses Experiments were repeated at least three times with consistent results. All our data were presented as the mean \pm SD. $p<0.05$ was considered significant.

\section{Results}

The anticancer efficacy of curcumin is correlated with the levels of maspin in prostate cancer cells. The expression levels of maspin in PC-3 and DU-45 cells were determined by Western blotting. As shown in Figure 1A, maspin had 
higher expression levels in PC-3 cells than in DU-145 cells. Furthermore, the $\mathrm{IC}_{50}$ of curcumin in PC-3 and DU- 145 cells was determined by the MTT assay. PC-3 cells were more sensitive to curcumin-induced cell death than DU-145 cells (Figure 1B). Our results suggested that maspin may have the potential to alter the drug-sensitivity of HRPC to curcumin.

Down-regulation of maspin decreases the efficacy of curcumin. To analyze functions of maspin on the efficacy of curcumin in HRPC, we generated maspin knockdown PC-3 cells (maspin-KD) using silencing hairpin RNA (shRNA). Figure $2 \mathrm{~A}$ shows that the expression of maspin was significantly repressed ( 0.23 fold $)$ in maspin-KD cells, respectively, compared with the scrambled control cells. To further confirm the role of maspin in the cytotoxic effect of curcumin, scrambled control and maspin-KD PC-3 cells were incubated with different doses of curcumin. The cell survival rate in maspin-KD cells treated with curcumin (20$30 \mu \mathrm{M})$ was significantly higher than that in scrambled control cells (Figure 2B), indicating that the knockdown of maspin may reduce the sensitivity of HRPC to curcumin.

Depletion of maspin reduces drug-sensitivity of PC-3 cells to curcumin. To confirm the effect of maspin-KD on curcumin-induced cell death, the influence on cell cycle distribution and apoptosis was analyzed by flow cytometry. Maspin-KD and scrambled control cells were treated with curcumin $(25 \mu \mathrm{M})$ and harvested at $48 \mathrm{~h}$. As shown in Figure 3 , the proportion of scrambled control cells in the subG1 phase was increased from $0.898 \%$ at $0 \mathrm{~h}$ to $17.5 \%$ at $48 \mathrm{~h}$ (Figure 3). Conversely, treatment of maspin-KD cells with curcumin showed a lower fraction in the sub-G1 phase (apoptotic cells) than the scrambled control cells. These findings suggested that maspin knockdown can protect PC3 cells from curcumin-induced cell death.

Silencing maspin diminishes curcumin-induced apoptosis in PC-3 cells. To further study the role of maspin-KD on curcumin-induced apoptosis, cells were treated with curcumin and subjected to the Annexin V/PI double-staining assay for flow cytometric analysis. The proportion of AnnexinV-positive/PI-negative (Annexin $\mathrm{V}^{+} / \mathrm{PI}^{-}, \quad \mathrm{Q} 1$ quadrant) and AnnexinV/PI-double positive cells (AnnexinV ${ }^{+} / \mathrm{PI}^{+}$, Q2 quadrant) were significantly higher in the scrambled control cells than in the maspin-KD cells after $48 \mathrm{~h}$ of treatment (Figure 4). These data suggested that maspin-KD PC-3 cells were more resistant to curcumininduced apoptosis than scrambled control cells.

Maspin knockdown affects curcumin-mediated apoptosis signaling in PC-3 cells. To characterize the mechanism of maspin knockdown on curcumin signaling, the expression levels of apoptosis-related proteins in response to curcumin
A
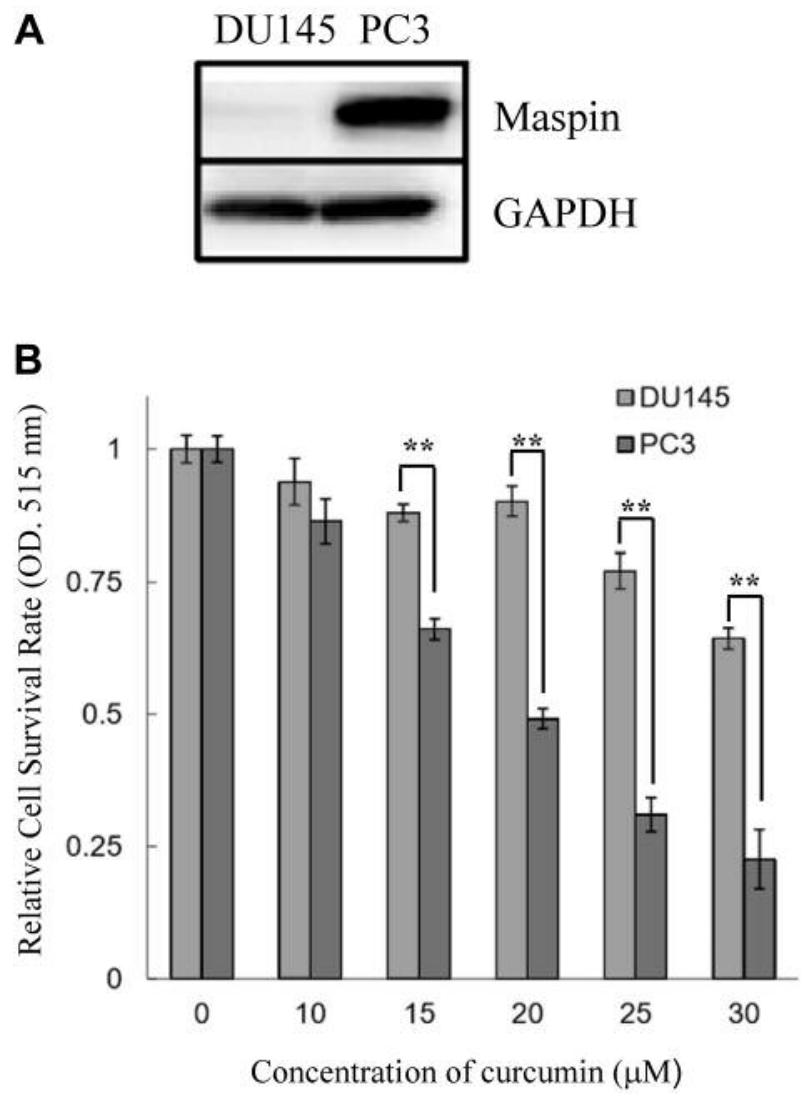

Figure 1. Expression levels of maspin are correlated with the sensitivity of prostate cancer cells to curcumin. (A) The expression level of maspin in PC-3 and DU-145 cells was analyzed by Western blotting. (B) PC-3 and $D U-145$ cells were treated with 0-30 $\mu \mathrm{M}$ curcumin for $48 \mathrm{~h}$. The effect of curcumin on the viability of prostate cancer cells (PC-3 and $D U-145$ cells) was determined by a MTT assay. All of the experiments were independently repeated at least three times. ${ }^{* *} p<0.01$.

were analyzed. Maspin-KD PC-3 and control cells were treated with curcumin for $48 \mathrm{~h}$, and the expression levels of anti-apoptotic proteins (myeloid cell leukemia 1 (Mcl-1) and B cell lymphoma 2 (Bcl-2)) and pro-apoptotic molecules (Bax and Bad) were detected using Western blotting. As shown in Figures 5A and 5B, Bax protein level decreased more significantly in curcumin-treated maspin-KD cells than in curcumin-treated scramble control. In addition, the Bad expression level was increased by $20 \%$ in curcumin-treated scrambled control cells but decreased in curcumin-treated maspin-KD cells (Figure 5A and B). These results were consistent with reducing the sensitivity of PC-3 cells to curcumin after maspin silencing. Thus, our findings suggested that maspin-KD induced inhibition of curcumin activity might be through reducing the expression of $\mathrm{Bax}$ and Bad in PC-3 cells. 
A

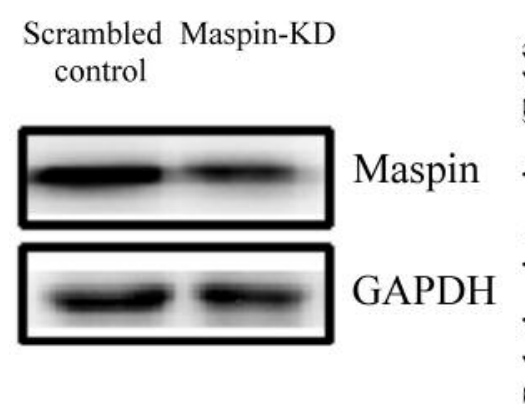

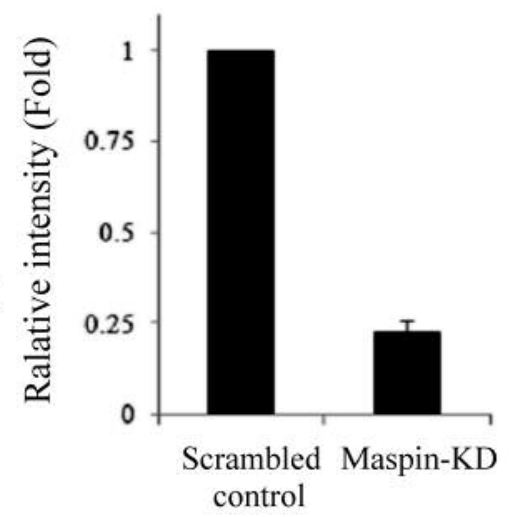

control

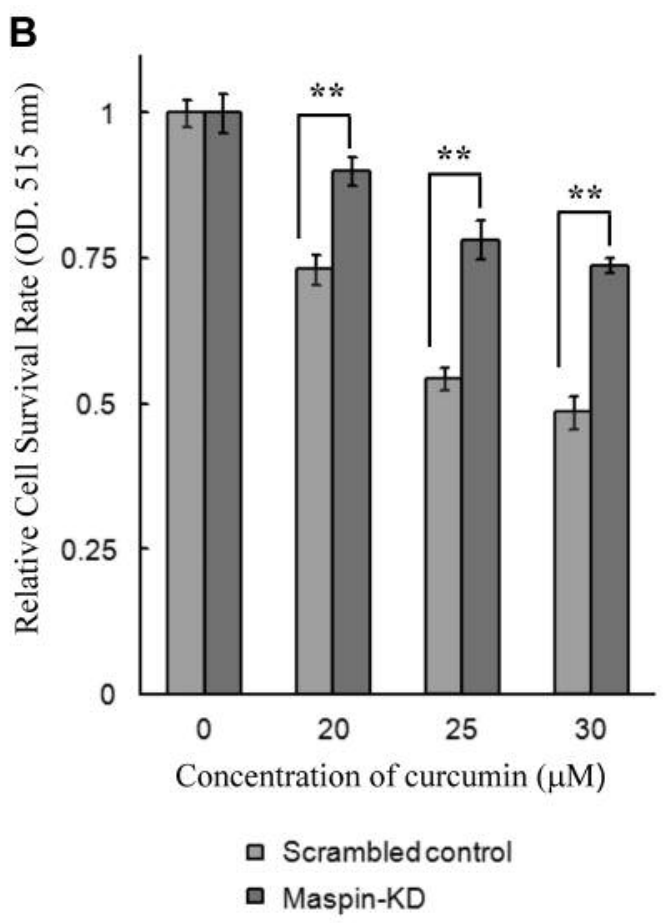

Figure 2. Silencing of maspin leads to decreased drug-sensitivity of PC-3 cells to curcumin. (A) The expression levels of maspin in the maspin-KD and scrambled control PC-3 cells were determined by Western blotting. (B) Maspin-KD and scrambled control cells were incubated with curcumin $(0-30$ $\mu M)$ for 48 h. Cell survival was determined using a MTT assay. All of the experiments were independently repeated at least three times. $* * p<0.01$.

\section{Discussion}

The progression of prostate cancer is dependent on activation of androgen receptor signaling. Presently, androgen deprivation therapy (ADT) is the first-line therapy for metastatic disease (28). Response to ADT, however, is temporary, and patients invariably progress to HRPC (29). Currently, there is no suitable treatment for HRPC. Curcumin, which has chemopreventive potential in cancers, suppresses the proliferation of both androgendependent and androgen-independent prostate cancer cells by interfering with growth factors, the cell cycle, and the metastasis potential (4). Furthermore, androgen ablation mediated-maspin induction was suggested to inhibit cell growth and induce apoptosis of prostate cancer cells (18). Additionally, curcumin has been shown to induce maspin expression to inhibit breast cancer cell invasion (21). Also, it was suggested that the efficacy of curcumin toward maspin expression might be modulated through the p53 pathway (13). These studies have emphasized the potential role of maspin in the activity curcumin-mediated anticancer therapy. In our study, we confirmed that PC-3 cells (high maspin expression) were more sensitive to curcumin-induced cell death than DU-145 cells (low maspin expression). Moreover, depletion of maspin inhibited curcumin-induced apoptosis in PC-3 cells. Besides, maspin silencing significantly decreased curcumin-induced apoptosis and reduced the percentage of AnnexinV-positive apoptotic cells. The extent of reduction of Bax was larger in the curcumin-treated maspin-KD cells than in curcumin-treated scrambled control cells (Figure 5). In addition, the expression level of Bad was increased in curcumin-treated scrambled control cells but decreased in curcumin-treated maspin-KD cells. Thus, we provided evidence for the first time that knockdown of maspin leads to a decreased sensitivity of HRPC to curcumin-induced apoptosis.

Curcumin shows pivotal role in the prevention of diseases including cancer (30). Accumulated evidence has indicated that curcumin is highly pleiotropic with anti-inflammatory (31), antioxidant (32), and anticancer activities $(4,30)$. Numerous clinical studies have demonstrated that curcumin has activity against several cancer types, such as colorectal cancer, pancreatic cancer, breast cancer, prostate cancer, multiple myeloma, lung cancer, oral cancer, and head and neck squamous cell carcinoma (33). The potent anticancer property of curcumin is related to its ability to simultaneously modulate the functions of a number of different molecular pathways including MAPK, EGFR and NFxB pathways (34). In addition, curcumin might elicit its growth inhibitory effects 

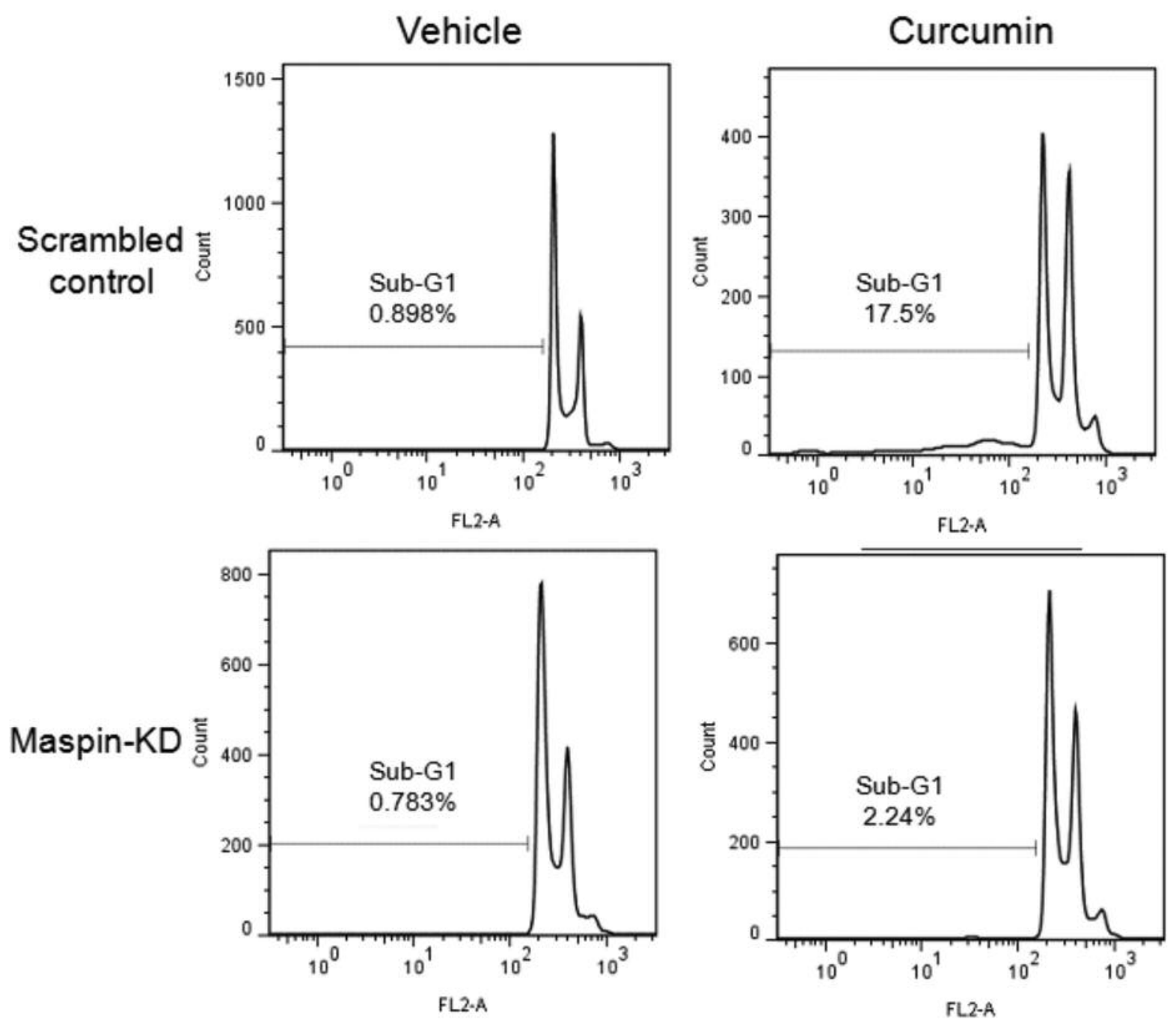

Figure 3. Maspin silencing inhibits curcumin-induced apoptosis in PC-3 cells. The cell-cycle distribution was assessed in scrambled control and maspin-KD PC-3 cells exposed to $25 \mu \mathrm{M}$ curcumin for $48 \mathrm{~h}$. Cells were collected and stained with PI. The cell-cycle distribution of each sample was determined by flow cytometry. All experiments were repeated at least three times. $p<0.05$.

through inhibition of $\mathrm{Wnt} / \mathrm{GSK}-3 \beta / \beta$-catenin pathway, which resulted in the destabilization of $\beta$-catenin proteins, downregulation of cyclin D1 and c-myc expression (35). Previous observations also demonstrated that curcumin is a promising agent for the treatment of both androgen-dependent (LNCaP) and androgen-independent (PC-3) prostate cancer cells (36). Besides, curcumin has been shown to down-regulate the expression of $\mathrm{AR}$ and $\mathrm{AR}$-related cofactors in prostate cancer cells (7). Curcumin suppresses cancer proliferation, migration, and invasion through the down-regulation of the JAK/STAT3 pathway (37). Furthermore, curcumin induces apoptosis involving Bax/Bcl-2 in human cancer cells (38). However, the role of maspin on curcumin-induced cell death in androgenindependent prostate cancer cells has not been elucidated. Our results suggested that maspin-KD induces curcumin resistance in PC-3 cells by modulating Bax and Bad expression.

Several clinical studies have shown that maspin downregulation correlates primarily with cancer progression and that maspin expression level correlates with better prognosis and better overall patient survival (39-41). In some cancer types, the expression level of maspin has been connected with cell differentiation, apoptosis, and invasion suppression $(42,43)$. However, the role of maspin in the drug sensitivity of HRPC cells to curcumin is still poorly understood. In our study, we demonstrated that knockdown of maspin expression reduced the sensitivity to curcumin. In addition, we discovered that the expression of Bax and Bad were down-regulated in curcumin-treated maspin-KD cells when 


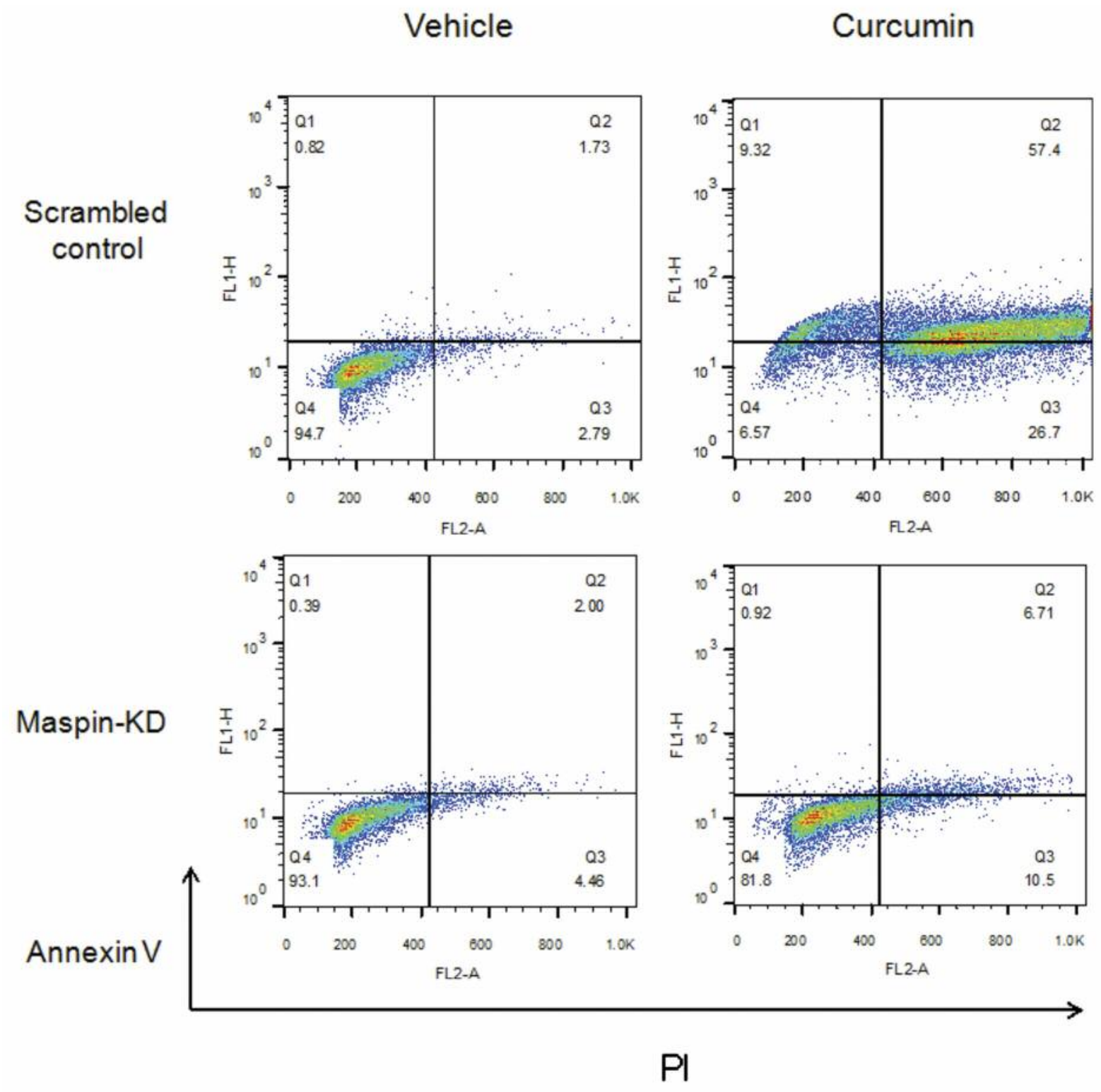

Figure 4. Maspin knockdown suppresses curcumin-induced apoptosis in PC-3 cells. After curcumin (25 $\mu M)$ treatment for 48 h, the maspin-KD cells and scrambled control cells were collected and subjected to AnnexinV/PI double staining. The AnnexinV ${ }^{+} / P I^{-}$cells (Q1 quadrant) and Annexin $V^{+} / P I^{+}$cells (Q2 quadrant) were then analyzed by flow cytometry. All experiments were repeated at least three times. $p<0.05$.

compared with control. Moreover, there is evidence suggested that Bad may possibly represent a possible positive prognostic marker and potential therapeutic target for androgen-independent prostate cancer (44). Our results implied that maspin might modulate the curcumin-induced cell death though alternations of Bax and Bad.

In conclusion, our results suggested a pivotal role of maspin in the sensitivities of HRPC cells to curcumin treatment. In particular, our results demonstrated that maspin depletion had a drug-resistance effect through modulating Bax and Bad expression in PC-3 cells, leading to inhibition of curcumin-induced cell death. As a result, we believe that these findings can help improve the therapeutic efficacy of curcumin in HRPC patients.

\section{Conflicts of Interest}

All Authors declare that there is no conflict of interest. 
A

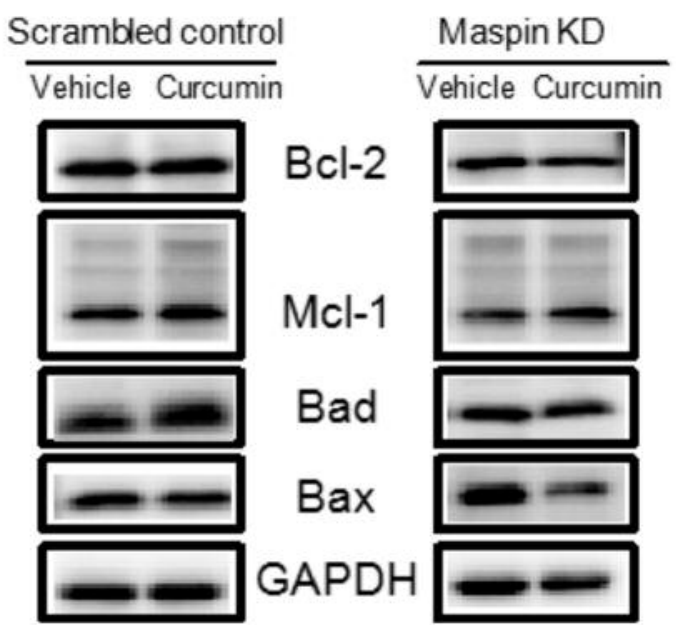

B
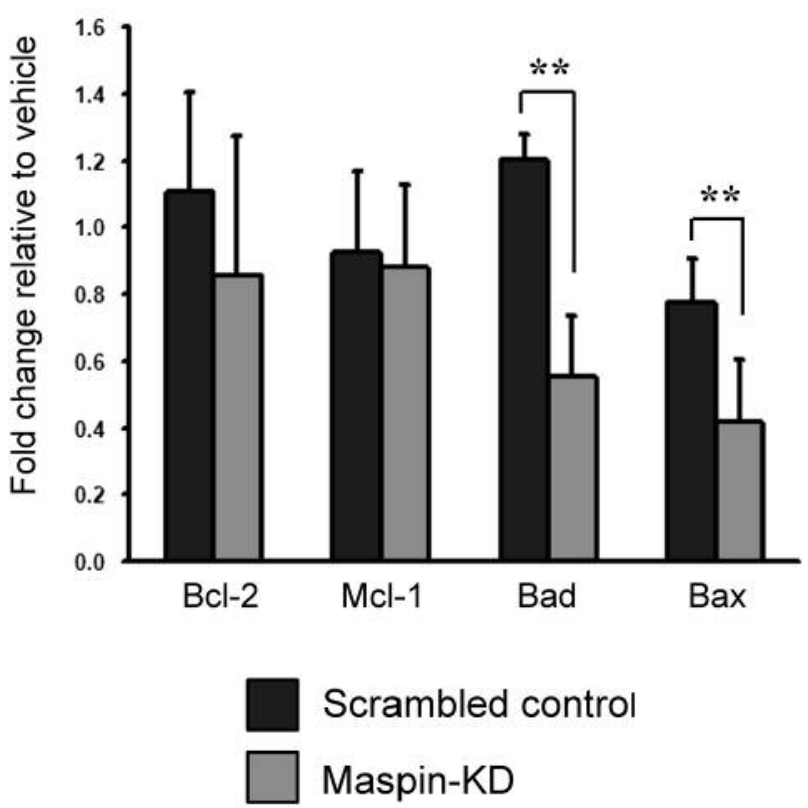

Figure 5. Maspin silencing reduces curcumin toxicity through downregulation of Bax and Bad. Following 48 h of treatment with curcumin $(25 \mu M)$, the maspin-KD and scrambled control PC-3 cells were harvested to extract total proteins. (A, B) Expression levels of Mcl-l, $B c l-2, B a x, B a d$, and GAPDH were examined using western blotting. GAPDH was used as an internal control. All experiments were repeated at least three times and data were presented as mean $\pm S D$. **p<0.01.

\section{References}

1 Siegel R, Naishadham D and Jemal A: Cancer statistics, 2012. CA Cancer J Clin 62(1): 10-29, 2012.

2 Lonergan PE and Tindall DJ: Androgen receptor signaling in prostate cancer development and progression. J Carcinog 10: 20, 2011.
3 Hotte SJ and Saad F: Current management of castrate-resistant prostate cancer. Curr Oncol 17(Suppl 2): S72-79, 2010.

4 Teiten MH, Gaascht F, Eifes S, Dicato M and Diederich M: Chemopreventive potential of curcumin in prostate cancer. Genes Nutr 5(1): 61-74, 2010.

5 Anand P, Thomas SG, Kunnumakkara AB, Sundaram C, Harikumar KB, Sung B, Tharakan ST, Misra K, Priyadarsini IK, Rajasekharan KN and Aggarwal BB: Biological activities of curcumin and its analogues (congeners) made by man and mother nature. Biochem Pharmacol 76(11): 1590-1611, 2008.

6 Kunnumakkara AB, Anand P and Aggarwal BB: Curcumin inhibits proliferation, invasion, angiogenesis and metastasis of different cancers through interaction with multiple cell signaling proteins. Cancer Lett 269(2): 199-225, 2008.

7 Nakamura K, Yasunaga Y, Segawa T, Ko D, Moul JW, Srivastava S and Rhim JS: Curcumin down-regulates ar gene expression and activation in prostate cancer cell lines. Int $\mathbf{J}$ Oncol 21(4): 825-830, 2002.

8 Ohtsu H, Xiao Z, Ishida J, Nagai M, Wang HK, Itokawa H, Su CY, Shih C, Chiang T, Chang E, Lee Y, Tsai MY, Chang C and Lee KH: Antitumor agents. 217. Curcumin analogues as novel androgen receptor antagonists with potential as anti-prostate cancer agents. J Med Chem 45(23): 5037-5042, 2002.

9 Saha S, Adhikary A, Bhattacharyya P, Das T and Sa G: Death by design: Where curcumin sensitizes drug-resistant tumours. Anticancer Res 32(7): 2567-2584, 2012.

10 Troselj KG and Kujundzic RN: Curcumin in combined cancer therapy. Curr Pharm Des 20(42): 6682-6696, 2014.

11 Chen QH: Curcumin-based anti-prostate cancer agents. Anticancer Agents Med Chem 15(2): 138-156, 2015.

12 Maass N, Nagasaki K, Ziebart M, Mundhenke C and Jonat W: Expression and regulation of tumor suppressor gene maspin in breast cancer. Clin Breast Cancer 3(4): 281-287, 2002.

13 Berardi R, Morgese F, Onofri A, Mazzanti P, Pistelli M, Ballatore Z, Savini A, De Lisa M, Caramanti M, Rinaldi S, Pagliaretta S, Santoni M, Pierantoni $\mathrm{C}$ and Cascinu S: Role of maspin in cancer. Clin Transl Med 2(1): 8, 2013.

14 Song SY, Son HJ, Kim MH, Nam ES, Rhee JC and Park C: Prognostic significance of maspin expression in human gastric adenocarcinoma. Hepatogastroenterology 54(75): 973-976, 2007.

15 Maass N, Hojo T, Ueding M, Luttges J, Kloppel G, Jonat W and Nagasaki K: Expression of the tumor suppressor gene maspin in human pancreatic cancers. Clin Cancer Res 7(4): 812-817, 2001.

16 Ito Y, Yoshida H, Tomoda C, Uruno T, Takamura Y, Miya A, Kobayashi K, Matsuzuka F, Matsuura N, Kuma K and Miyauchi A: Maspin expression is directly associated with biological aggressiveness of thyroid carcinoma. Thyroid 14(1): 13-18, 2004.

17 Umekita Y, Souda M and Yoshida H: Expression of maspin in colorectal cancer. In Vivo 20(6B): 797-800, 2006.

18 Zou Z, Zhang W, Young D, Gleave MG, Rennie P, Connell T, Connelly R, Moul J, Srivastava S and Sesterhenn I: Maspin expression profile in human prostate cancer (cap) and in vitro induction of maspin expression by androgen ablation. Clin Cancer Res 8(5): 1172-1177, 2002.

19 Zhang M, Volpert O, Shi YH and Bouck N: Maspin is an angiogenesis inhibitor. Nat Med 6(2): 196-199, 2000.

20 Shi P, Chen WW, Hu XY, Yu CX, Zhang PJ, Jiang AL and Zhang JY: Up-regulates the expression of maspin gene in prostate cancer cell line Incap. Yao Xue Xue Bao 41(12): 11521156, 2006. 
21 Prasad CP, Rath G, Mathur S, Bhatnagar D and Ralhan R: Expression analysis of maspin in invasive ductal carcinoma of breast and modulation of its expression by curcumin in breast cancer cell lines. Chem Biol Interact 183(3): 455-461, 2010.

22 Bernardo MM, Kaplun A, Dzinic SH, Li X, Irish J, Mujagic A, Jakupovic B, Back JB, Van Buren E, Han X, Dean I, Chen YQ, Heath E, Sakr W and Sheng S: Maspin expression in prostate tumor cells averts stemness and stratifies drug sensitivity. Cancer Res 75(18): 3970-3979, 2015.

23 Chang YJ, Huang CY, Hung CS, Liu HH and Wei PL: Glucoseregulated protein 78 mediates the therapeutic efficacy of $17-$ dmag in colon cancer cells. Tumour Biol 36(6): 4367-4376, 2015.

24 Bradford MM: A rapid and sensitive method for the quantitation of microgram quantities of protein utilizing the principle of protein-dye binding. Anal Biochem 72: 248-254, 1976.

25 Chiou JF, Tai CJ, Huang MT, Wei PL, Wang YH, An J, Wu CH, Liu TZ and Chang YJ: Glucose-regulated protein 78 is a novel contributor to acquisition of resistance to sorafenib in hepatocellular carcinoma. Ann Surg Oncol 17(2): 603-612, 2010.

26 Kuo LJ, Huang CY, Cheng WL, Hung CS, Wu CT, Lin FY, Chang YJ and Huang MT: Glucose-regulated protein 78 mediates the anticancer efficacy of shikonin in hormonerefractory prostate cancer cells. Tumour Biol 36(7): 5063-5070, 2015.

27 Cornelissen M, Philippe J, De Sitter S and De Ridder L: Annexin $\mathrm{v}$ expression in apoptotic peripheral blood lymphocytes: An electron microscopic evaluation. Apoptosis 7(1): 41-47, 2002.

28 Alva A and Hussain M: Intermittent androgen deprivation therapy in advanced prostate cancer. Curr Treat Options Oncol 15(1): 127-136, 2014.

29 Rini BI and Small EJ: Hormone-refractory prostate cancer. Curr Treat Options Oncol 3(5): 437-446, 2002.

30 Kasi PD, Tamilselvam R, Skalicka-Wozniak K, Nabavi SF, Daglia M, Bishayee A, Pazoki-Toroudi $\mathrm{H}$ and Nabavi SM: Molecular targets of curcumin for cancer therapy: An updated review. Tumour Biol 37(10): 13017-13028, 2016.

31 Gupta SC, Kim JH, Prasad S and Aggarwal BB: Regulation of survival, proliferation, invasion, angiogenesis, and metastasis of tumor cells through modulation of inflammatory pathways by nutraceuticals. Cancer Metastasis Rev 29(3): 405-434, 2010.

32 Menon VP and Sudheer AR: Antioxidant and anti-inflammatory properties of curcumin. Adv Exp Med Biol 595: 105-125, 2007.

33 Gupta SC, Patchva S and Aggarwal BB: Therapeutic roles of curcumin: Lessons learned from clinical trials. AAPS J 15(1): 195-218, 2013.

34 Mukhopadhyay A, Bueso-Ramos C, Chatterjee D, Pantazis P and Aggarwal BB: Curcumin downregulates cell survival mechanisms in human prostate cancer cell lines. Oncogene 20(52): 7597-7609, 2001.
35 Choi HY, Lim JE and Hong JH: Curcumin interrupts the interaction between the androgen receptor and wnt/beta-catenin signaling pathway in lncap prostate cancer cells. Prostate Cancer Prostatic Dis 13(4): 343-349, 2010.

36 Guo H, Xu YM, Ye ZQ, Yu JH and Hu XY: Curcumin induces cell cycle arrest and apoptosis of prostate cancer cells by regulating the expression of ikappabalpha, c-jun and androgen receptor. Pharmazie 68(6): 431-434, 2013.

37 Senft C, Polacin M, Priester M, Seifert V, Kogel D and Weissenberger $\mathrm{J}$ : The nontoxic natural compound curcumin exerts anti-proliferative, anti-migratory, and anti-invasive properties against malignant gliomas. BMC Cancer 10: 491, 2010.

38 Yu J, Zhou X, He X, Dai M and Zhang Q: Curcumin induces apoptosis involving bax/bcl-2 in human hepatoma smmc-7721 cells. Asian Pac J Cancer Prev 12(8): 1925-1929, 2011.

39 Machtens S, Serth J, Bokemeyer C, Bathke W, Minssen A, Kollmannsberger C, Hartmann J, Knuchel R, Kondo M, Jonas $\mathrm{U}$ and Kuczyk M: Expression of the p53 and maspin protein in primary prostate cancer: Correlation with clinical features. Int $\mathbf{J}$ Cancer 95(5): 337-342, 2001.

40 Wang Y, Sheng S, Zhang J, Dzinic S, Li S, Fang F, Wu N, Zheng $\mathrm{Q}$ and Yang Y: Elevated maspin expression is associated with better overall survival in esophageal squamous cell carcinoma (escc). PLoS One 8(5): e63581, 2013.

41 Yoshizawa K, Nozaki S, Okamune A, Kitahara H, Ohara T, Kato $\mathrm{K}$, Kawashiri $\mathrm{S}$ and Yamamoto E: Loss of maspin is a negative prognostic factor for invasion and metastasis in oral squamous cell carcinoma. J Oral Pathol Med 38(6): 535-539, 2009.

42 Bernardo MM, Meng Y, Lockett J, Dyson G, Dombkowski A, Kaplun A, Li X, Yin S, Dzinic S, Olive M, Dean I, Krass D, Moin K, Bonfil RD, Cher M, Sakr W and Sheng S: Maspin reprograms the gene expression profile of prostate carcinoma cells for differentiation. Genes Cancer 2(11): 1009-1022, 2011.

43 Zhu H, Mao Q, Liu W, Yang Z, Jian X, Qu L and He C: Maspin suppresses growth, proliferation and invasion in cutaneous squamous cell carcinoma cells. Oncol Rep 37(5): 2875-2882, 2017.

44 Teo K, Gemmell L, Mukherjee R, Traynor P and Edwards J: Bad expression influences time to androgen escape in prostate cancer. BJU Int 100(3): 691-696, 2007.
Received November 18, 2017

Revised December 3, 2017

Accepted December 4, 2017 